Discussion

Papers

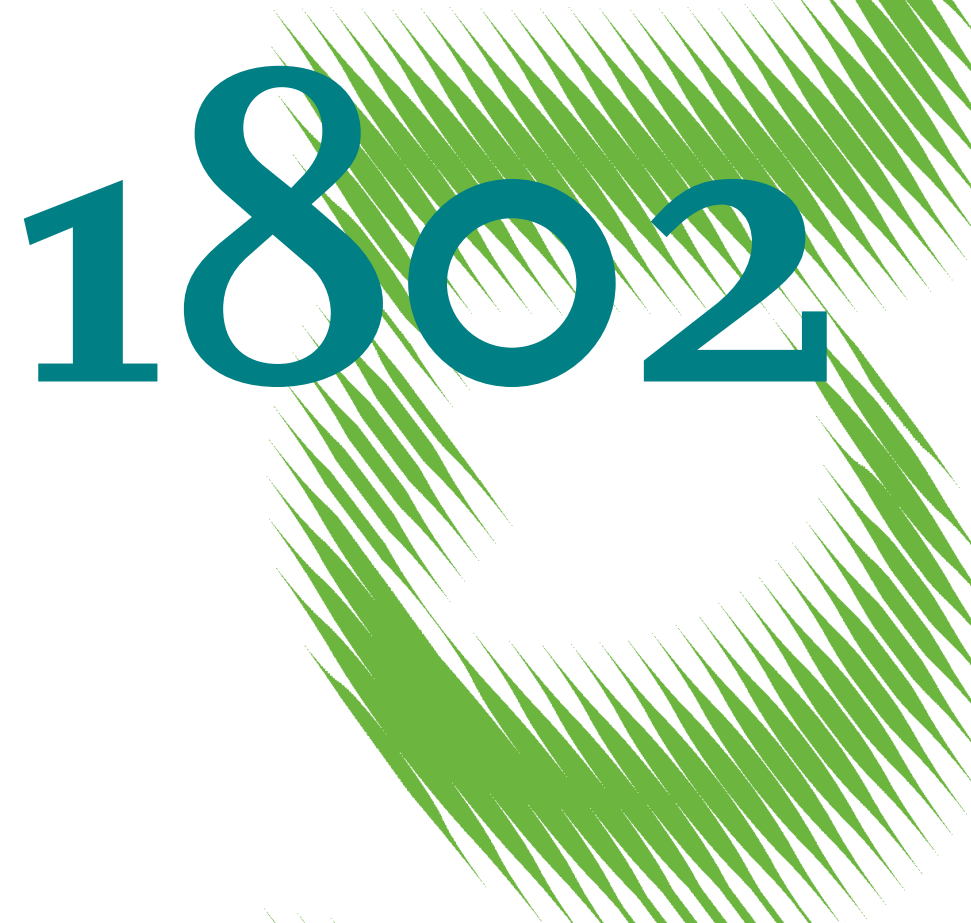

Increased Instruction Time and Stress-Related Health Problems among School Children 
Opinions expressed in this paper are those of the author(s) and do not necessarily reflect views of the institute.

IMPRESSUM

(C) DIW Berlin, 2019

DIW Berlin

German Institute for Economic Research

Mohrenstr. 58

10117 Berlin

Tel. +49 (30) $89789-0$

Fax +49 (30) $89789-200$

http://www.diw.de

ISSN electronic edition 1619-4535

Papers can be downloaded free of charge from the DIW Berlin website:

http://www.diw.de/discussionpapers

Discussion Papers of DIW Berlin are indexed in RePEc and SSRN:

http://ideas.repec.org/s/diw/diwwpp.html

http://www.ssrn.com/link/DIW-Berlin-German-Inst-Econ-Res.html 


\title{
Increased instruction time and stress-related health problems among school children
}

\author{
Jan Marcus,, Simon Reif, Amelie Wuppermann, Amélie Rouche ${ }^{\S}$
}

April 2019

\begin{abstract}
While several studies suggest that stress-related mental health problems among school children are related to specific elements of schooling, empirical evidence on this causal relationship is scarce. We examine a German schooling reform that increased weekly instruction time and study its effects on stress-related outpatient diagnoses from the universe of health claims data of the German Social Health Insurance. Exploiting the differential timing in the reform implementation across states, we show that the reform slightly increased stress-related health problems among school children. While increasing instruction time might increase student performance, it might have adverse effects in terms of additional stress.
\end{abstract}

Keywords: stress, mental health, instruction time, G8 reform

fEL: $\quad$ I18, I28

\footnotetext{
*University of Hamburg \& DIW Berlin (jan.marcus@uni-hamburg.de)

†University of Erlangen-Nuremberg \& RWI Essen (simon.reif@fau.de)

¥MLU Halle-Wittenberg (amelie.wuppermann@wiwi.uni-halle.de)

§Zentralinstitut für die kassenärztliche Versorgung (ARouche@zi.de)
}

The data used in this study are provided by the German Central Institute of the National Association of Statutory Health Insurance Physicians (Zentralinstitut für die kassenärztliche Versorgung; Zi). We are particularly grateful to Jörg Bätzing of the Zi for his valuable support with the data. Funding through the International Doctoral Program, "Evidence-Based Economics," of the Elite Network of Bavaria is gratefully acknowledged. 


\section{Introduction}

Child wellbeing is long on the agenda of both researchers and policy makers (WHO, 2016). While mental health problems, in general, and stress, in particular, are identified as detrimental factors to wellbeing in childhood and adolescence (Bor et al., 2014), mental health problems among children and adolescents increased in the last decades (Collishaw et al., 2004; Collishaw, 2015). Several studies argue that schooling substantially contributes to the high stress prevalence and stress-related mental health problems. For example, youth suicide rates increase at the beginning of the school year (Lahti et al., 2005; Matsubayashi et al., 2016) and, generally, are higher while school is in session (Hansen and Lang, 2011). Further, there is evidence that academic stress increases suicidal ideation (Ang and Huan, 2006). Although stress in school rarely leads to extreme outcomes, such as (attempted) suicide, students report that school is the biggest stressor in their lives (Elias, 1989; de Anda et al., 2000; Baltimore Center for Adolescent Health, 2006). However, it is unclear which elements of schooling and the schooling system drive the observed patterns. ${ }^{1}$

In this paper, we contribute to the literature on schooling and mental health by investigating the causal effect on stress-related mental health problems of a specific element of the schooling system, namely weekly instruction time. More specifically, we exploit a German schooling reform that substantially increased weekly instruction time. The differential timing of the reform across German states allows us to estimate the causal effect of more weekly instruction time using a difference-in-differences approach. Based on the universe of outpatient diagnoses from health claims data of the German Social Health Insurance system, we find evidence that more instruction time increases stress-related outpatient diagnoses slightly, albeit statistically significantly.

Several empirical studies document associations between schooling and students' self-reported mental health. ${ }^{2}$ For instance, Leung et al. (2010) report that high academic pressure is associated with high anxiety levels. Similarly, Löfstedt (2017) finds that increased pressure in school relates to higher rates of psychosomatic symptoms. Freeman et al. (2012) find that a negative school climate correlates with high levels of psychosomatic complaints. Further, Torsheim and Wold (2001) show that somatic

\footnotetext{
${ }^{1}$ Apart from elements of the schooling system, peers might also affect mental health and stress of students, e.g., through bullying (Eriksen et al., 2014). Further, schooling might not only have negative consequences for stress and mental health, but it might also have protecting effects. For instance, children who experience a lot of stress at home might be more stressed during school holidays, with school potentially being a place to gain resilience.

${ }^{2}$ All these studies focus on the effect of schooling on mental health when students are in school. There is also a distinct literature focusing on the long-run effects of education on mental health (as a potential non-monetary return to education). These studies have a different focus compared to our study, as we are mainly interested in explaining youth mental health issues.
} 
symptoms, such as headache, abdominal pain, backache, and dizziness, are common when perceived school-related stress is high. In line with these results are the findings of Ravens-Sieberer et al. (2009), who show that there is a positive relationship between better school perceptions and higher self-assessed health. Other studies focus on associations between specific elements of the schooling system and measures of mental health. For instance, Galloway et al. (2013) document that students are more stressed when they need more time to complete their homework. Similarly, there is evidence that students are more stressed during exam periods (Banks and Smyth, 2015), while the amount of school sport (Jewett et al., 2014) and good teacher-student relationships (Conner et al., 2014) relate to better self-reported measures of mental health.

There is also research on the causal effects of schooling on measures of mental health. For instance, Song (2017) applies a regression discontinuity design in the admission to elite colleges in China and finds that attending an elite college increases selfreported measures of stress. Heissel et al. (2018) provide evidence that cortisol levels, as an indicator of stress, increase during high-stakes testing weeks. King et al. (2014) demonstrate that adolescents in the US receive more stimulant prescriptions during the school year. They further show that states with stricter accountability laws have the largest differences in stimulant prescriptions between school year and summer, which suggests that there is a high level of self-medication in states with less restrictive accountability laws. Results from Bokhari and Schneider (2011) support this claim by showing that stricter accountability laws increase diagnosis and medication for ADHD. ${ }^{3}$ The studies by Bokhari and Schneider (2011) and King et al. (2014) are most similar to our study regarding the aim to identify causal effects and the focus on more objective health measures that are not self-reported by the individuals. However, while these studies examine differences between school and holiday season and effects of school accountability laws, we focus on the effects of a different element of the schooling system, instruction time. Moreover, these studies look at psychostimulant prescription, we study stress-related diagnoses.

This paper contributes to the existing literature along three dimensions. First, while many previous studies focus on correlations, our difference-in-differences strategy aims to identify causal effects. Second, instead of examining self-reported stress-related mental health problems, we rely on outpatient diagnoses of stress-related diseases and, thus, a more objective measure. Third, we do not look at schooling in general but rather focus on one key feature of the schooling system - weekly instruction time. The remainder of this paper is structured as follows: Next we provide an overview of the schooling re-

\footnotetext{
${ }^{3}$ Additionally, students might be prescribed drugs due to unobservable factors, such as their relative age, independent of stress in school. Schwandt and Wuppermann (2016), for example, show that ADHD medication is more frequently prescribed when children start school younger.
} 
form we exploit (Section 2). Section 3 outlines the data we use and the empirical strategy, while Section 4 presents the results and robustness checks. Section 5 concludes.

\section{Institutional Background}

In order to analyze the mental health effects of weekly instruction time, we exploit a major reform in German secondary schools. In the course of this reform, the majority of German states shortened their academic track from nine to eight years, reducing total school years from 13 to 12 (the so called G8 reform). This reduction in school years took place early in the new millennium and was compensated by an increase of weekly instruction time in the remaining school years. For grades 5-10, the focus of this paper, this increase amounts to one to three schooling hours (45 minutes) per week (see Figure 1). On average, weekly instruction time increases by slightly more than two hours, which amounts to less than $10 \%$ of the overall weekly instruction time, which is about 30 hours. The increase in weekly instruction time is used to compensate for the one year reduction in school years by spreading content over earlier school years. Naturally, the G8 reform increased the speed at which students must cope with the content learned. The switch from the previous regime (G9) to the new regime (G8) affected only the academic track school (Gymnasium), which is the high ability track that prepares for university studies. This track is attended by about $35 \%$ of a cohort according to representative survey data (see Figure A.1 in the Appendix). Weekly instruction time and the length of the schooling period remained constant in the other school tracks.

The G8 reform constitutes a natural experiment as different federal states implemented it in different years (see Table 1). This policy experiment is already exploited in several studies, mainly regarding students' behavior and academic outcomes. For instance, Huebener et al. (2017) find that the reform increased academic performance in school due to the higher weekly instruction time in the lower grades. However, this effect is mainly driven by high-performing students; lower-performing students benefit less from the additional instruction time. The finding that some students have trouble in coping with the additional instruction time and learning material is underlined by the finding of Huebener and Marcus (2017), who show that more students repeat a grade due to the reform. This finding also can be interpreted as suggestive evidence that the G8 reform increases stress. At the end of schooling, several studies document slightly lower performance of the G8 students (Büttner and Thomsen, 2015; Huebener and Marcus, 2017; Hübner et al., 2017), suggesting that the additional instruction time in lower grades does not fully compensate for the omitted last year. Further, there is some evidence that the reform affected cognitive skills (Dahmann, 2017), but only margin- 
ally affected personality traits (Dahmann and Anger, 2014; Thiel et al., 2014). Affected students had also less leisure time (Meyer and Thomsen, 2015; Hübner et al., 2017). Further, the reform resulted in delayed university enrollment for some students (Meyer and Thomsen, 2016; Marcus and Zambre, 2018) and slightly reduced enrollment rates (Marcus and Zambre, 2018). However, affected students graduated earlier from high school (Huebener and Marcus, 2017) and enrolled in university at significantly younger ages (Marcus and Zambre, 2018), thereby allowing for an earlier labor market entry.

While existing research focuses mainly on students' behavior and academic outcomes, parents and students were strongly concerned about higher stress levels due to the reform's increase in weekly instruction time. These concerns - although based on subjective feelings and anecdotal evidence - were articulated widely in the media (see, e.g., Die Welt, 2016; F.A.Z., 2014; Spiegel Online, 2016) and prompted several states to repeal the reform (see Table 1). Other states are also considering repealing the reform. The decisions to switch back were not based on scientific studies (Huebener and Marcus, 2015; Thomsen and Anger, 2018), although there is initial evidence on the health effects of the reform based on survey data. Quis and Reif (2017), Quis (2018), and Hofmann and Mühlenweg (2018) find some evidence for increased stress, in particular among females, while Milde-Busch et al. (2010) do not find any health differences between reform and control groups in a cross-sectional study. All these studies are based on small samples and self-reported measures of stress. However, these subjective measures of students' health could be influenced by parental opinions and the general public's ongoing discussion regarding the reform. ${ }^{4}$ To date, no empirical study analyzes the effects of increased instruction intensity on objective stress-related health measures. In this paper, we extend the existing survey evidence by estimating the effect of increased instruction time on stress-related health problems of students by using administrative data.

\section{Data and empirical strategy}

For our outcome measure, we make use of administrative data on outpatient diagnoses. The data is provided by Zentralinstitut für die kassenärztliche Versorgung ( $\mathrm{Zi}$ ), on behalf of the National Association of Statutory Health Insurance Physicians, and covers the universe of outpatient diagnoses from health claims data of the German Social Health Insurance (SHI). The German SHI covers about 70 million individuals (German Federal Ministry of Health, 2018), which amounts to about $87 \%$ of the population across all age

\footnotetext{
${ }^{4}$ There is plenty of anecdotal evidence that children affected by the reform were repeatedly asked by parents and relatives whether they feel stressed by this new system, which was widely discussed in the media.
} 
groups. ${ }^{5}$ Hence, our data does not include information about doctor visits by privately insured individuals. Further, doctor visits due to accidents at school/work or on the way to school/work are not covered by the SHI system and, therefore, not included in our data set. ${ }^{6}$ Our data includes information about an individual's outpatient diagnoses (ICD-10 codes) in a given calendar year, the individual's month and year of birth, as well as the county and state of residence.

The data set has two major strengths. The first is its large sample size: Our main analyses are based on more than 2.7 million children per year. The second advantage is that the relevant health information are provided by physicians. ${ }^{7}$ This means that our stress measure is medically relevant and not reported by the affected individuals themselves. Self-reported health measures are prone to reporting error, social desirability bias, mood effects, and strategic responses.

The data also has limitations. Data is only available for a limited number of years (2008-2011). Further, the data set does not provide any information on school track and school grade. While the G8 reform affected only the academic track, we have to assign the treatment indicator irrespective of the school track attended. Therefore, our estimates are likely biased toward zero and should be interpreted as intent-to-treat effects. In the robustness section, we discuss this issue in more detail and provide estimates for the effects if only academic-track students were considered. The information on the school grade is important for correctly assigning the G8 treatment indicator. We assign the school grade (and, hence, the treatment indicator) based on the individual's date of birth. This assignment rule assumes that individuals complied with the school entry rules and did not repeat or skip a grade. For cohorts directly before and after the introduction of the G8 reform, both non-compliance with the entry rules and grade repetition/skipping can lead to a misassignment of the reform indicator and, hence, a bias toward zero. However, the extent of the misassignment is clearly smaller than the misassignment resulting from the unknown track information. ${ }^{8}$

For additional computations, we use state-level information on the number of students in different tracks provided by the German Federal Statistical Office (German Federal Statistical Office, 2012) and survey data from the first wave of KiGGS, a nationwide health-survey among children conducted by the Robert Koch Institute in the years 2003-

\footnotetext{
${ }^{5}$ Survey data from the KiGGS (RKI, 2015) indicates that the share of children aged 18 or younger who are insured in the SHI is similar, at about $89 \%$ (see Table A.1 in the Appendix).

${ }^{6}$ These doctor visits are covered by the mandatory accident insurance.

${ }^{7}$ In Germany, physicians in outpatient care do not have financial incentives to assign specific diagnoses. Unlike in the German hospital sector, reimbursement does not depend on the diagnoses.

${ }^{8}$ Compliance with the age cut-offs for school entry is, at $86 \%$ (see Schwandt and Wuppermann, 2016), rather high in Germany. Further, the average grade repetition rate in academic-track schools is less than $2 \%$ in grades 5-10 (see German Federal Statistical Office, 2012). Huebener and Marcus (2017) also provide evidence that the G8 reform did not increase grade repetition before grade 10.
} 
2006 (RKI, 2015). ${ }^{9}$

\subsection{Sample}

We restrict our main analysis sample to individuals in grades 7 to 10 . This restriction is imposed for several reasons. First, some states track students only after six grades of joint primary schooling. Hence, by restricting our main sample to individuals in grades 7 and higher, we make sure that we look at an age range in which tracking has taken place in all states. Second, Figure 1 shows that the increase in instruction time is much greater in grades 7 to 10 than in grades 5 and 6. Third, schooling in Germany is compulsory through grade 10 in most states (Vossenkuhl, 2010) and in academic track schools almost all students stay at least until grade 10. After grade 10, some students decide not to pursue the general university entrance qualification but instead complete an apprenticeship. Hence, if the G8 reform impacts the share of academic track students who decide not to pursue the general university entrance qualification, students in grades 11 and 12 might be a selective group. Fourth, in the final two years at academic track schools students earn grades that count toward their final grade point average. This final grade point average is very important for the students because it is a major selection criterion for university admission. Therefore, the last two years might be especially stressful for students. However, under the G8 regime, grades 11 and 12 constitute the final two years, while the final years under the old system were grades 12 and 13 . Hence, any differences in stress-related diagnoses in a comparison of students in grade 11 under G8 and the old system might not results from additional instruction time but rather from the fact that the grades already count toward the final grade point average. Therefore, we do not consider students in grades 11 and 12 in our main specification. In the robustness section, we show, however, that our results are insensitive to including students from further grades as well. Overall, our main sample consists of more than 2.7 million children per year in grades 7-10.

\subsection{Outcome Measure}

Identifying stress-related health problems is challenging as stress is related to different health problems (Torsheim and Wold, 2001; Ravens-Sieberer et al., 2009). In our analysis, we use an index that captures and aggregates different possible health problems related to stress: The Disease based Stress Score (DbSS). The Stress Score, developed by Amélie Rouche at Zi (Rouche et al., 2017), is based on outpatient diagnoses by physi-

\footnotetext{
${ }^{9} \mathrm{We}$ use the KiGGS survey only for illustrative purposes as the number of observation at the stategrade level is to small for an analysis of the reform effect.
} 
cians. It does not measure stress directly, instead it uses diagnoses that, according to clinicians, indicate physiological stress. The Stress Score is constructed in four steps. In the first step, stress-related diagnoses (i.e., ICD-10 codes) are identified by experts from medicine, psychology, and epidemiology. The second step groups these more than 300 ICD-10 codes into 21 categories. The third step constructs, for each category, a binary variable that indicates whether an individual had at least one diagnosis in this category in the given calendar year. We refer to these 21 indicator variables as subscales. ${ }^{10}$ In supplementary empirical analyses, we also use these indicator variables as outcome variables. ${ }^{11}$ The fourth step constructs the actual Stress Score by summing over all these indicator variables. Hence, the range of possible values of the Stress Score is between 0 and 21.

In our main analysis sample, the average value of the Disease based Stress Score is 1.21 , the standard deviation is 1.36 . Figure 2 provides an overview of the distribution of the Stress Score for our analysis sample. We do not only take the overall Stress Score as outcome, but we also consider binary variables indicating whether the Stress Score is larger than $0,1,2$, and $3 .{ }^{12}$

\subsection{Empirical Strategy}

Our empirical strategy exploits variation in time and across states in a difference-indifferences framework to identify the effect of the G8 reform on stress-related diagnoses. More specifically, we estimate the following equation by OLS:

$$
y_{i c d g}=\beta G 8_{c d}+\kappa_{d}+\lambda_{c}+\mu_{g}+\varepsilon_{i c d g},
$$

where $y_{i c d g}$ denotes the value of the Disease based Stress Score for individual $i$ in cohort $c$ in county $d$ in grade $g, G 8_{c d}$ indicates whether cohort $c$ in county $d$ was subject to the G8 reform or not and $\beta$ is the coefficient of interest, providing the effect of the G8 reform on the Stress Score. $\kappa_{d}$ is a set of county fixed effects that takes general differences

\footnotetext{
${ }^{10}$ These subscales include cardiac arrhythmias; hypertension, cardiovascular problems; insomnia; sexual disorder; gastrointestinal disorders; eating disorders, weight loss/gain; head ache; back pain; depression; anxiety disorder; adjustment stress disorder; concentration disorders, exhaustion; tinnitus, sudden deafness, vertigo, aphonia; temporary vision disorders, eye lid convulsions; heightened susceptibility to infection, allergies; psychosomatic dermatosis; alcohol abuse and drug dependency; somatoform disorders; problematic social situation; behavioral and emotional disorders; learning disorders, developmental disorders. Each subscale includes only diagnoses of low severity and does not consider serious diseases.

${ }^{11}$ Due to data privacy, we do not have access to the individual ICD-10 based diagnoses.

${ }^{12}$ Supplementary data analysis with the KiGGS (RKI, 2015) survey show that subjective school satisfaction is significantly correlated with the Stress Score categories available in the survey data (see Figure A.1 in the Appendix).
} 
between counties into account, and, hence, also between states as each county belongs to a single state. These county fixed effects also take into account time-invariant regional differences in the coding behavior of physicians. $\lambda_{c}$ denotes cohort fixed effects and $\mu_{g}$ grade fixed effects. The latter two sets of fixed effects control for general differences between cohorts and across grades, respectively. $\varepsilon_{i c d g}$ is the error term and the computation of standard errors allows for clustering at the cohort-state level, the level at which the treatment indicator is determined.

While this is our main specification, we also present results based on estimations that include cohort-grade fixed effects and county-grade fixed effects. These two sets of fixed effects allow for grade-specific differences between counties and for grade-specific differences between cohorts, respectively. This specification includes a very large number of fixed effects (over 1500) and, therefore, we prefer the much more parsimonious specification with county, cohort and grade fixed effects for presentation of main results. As discussed below, the results are very similar when controlling for cohort-grade and county-grade fixed effects.

\section{Results}

\subsection{Main results}

Table 2 presents our estimates for the effect of the G8 reform on stress-related diagnoses. Controlling for cohort, county, and grade fixed effects the estimates in Panel A suggest that the Stress Score increased by 0.022 units following the introduction of the G8 reform. This statistically significant effect amounts to about $1.6 \%$ of a standard deviation of the Stress Score and is similar to the difference between the Stress Score of counties at the 50th and the 56th percentile in our sample. This suggests that the effect is rather small. Including cohort-grade fixed effects (column 2) and county-grade fixed effects (column 3) does not substantially alter the effects size. The other panels show that stress-related diagnoses increase at both the extensive and the intensive margin. The probability to have at least one stress-related diagnosis increased by 0.6 percentage points due to the G8 reform (Panel B). Compared to the sample share of $62.3 \%$, this amounts to an increase of about $1 \%$. Panels C, D, and E show that the G8 reform also significantly increased the probability that the Stress Score is larger than 1, 2, and 3, respectively. ${ }^{13}$

\footnotetext{
${ }^{13}$ When looking at the probability that the Stress Score is larger than 4 (not shown), we find a small but borderline significant effect. There is no evidence that the G8 reform also increased the probability that the Stress Score exceeds 5 (not shown). However, it is important to note that only few individuals in our sample have a Stress Score value larger than $5(1.2 \%)$.
} 
When further disentangling the results and taking the 21 subscales of the Stress Score as outcome variables, we see that no specific subscale drives the results. ${ }^{14}$ Instead, the G8 reform increases several subscales. In absolute terms, the strongest effects are found for eating disorders, headaches, and gastrointestinal disorders. However, several other subscales also exhibit significant increases. Eating disorders are also the subscale for which we obtain the largest relative increase: The reform-induced an increase in eating disorders of 0.7 percentage points, which amounts to an increase of about $11 \%$, relative to the sample share of $6.4 \%$ with eating disorders.

Looking at the effects separately by grades, Table 3 shows that all the estimated coefficients are positive suggesting that the G8 reform increased stress-related diagnoses across grades. However, the effect on the Stress Score is only statistically significant in grades 9 and 10, the grades that received the strongest increases in instruction time.

\subsection{Robustness}

In this section, we provide additional results for the robustness of our findings. Our data set does not allow for distinguishing between individuals in different school tracks. As the G8 reform only affected the academic track, our estimates can be seen as lower bounds of the true reform effect. For the estimations in column (2) of Table 4, we scale the treatment effect by the share of treated students in a state-cohort-grade cell. For this purpose, we aggregate the data at the state-cohort-grade level and interact the dummy G8-treatment indicator in equation (1) with the share of academic-track students in a state-cohort-grade cell. ${ }^{15}$ Unsurprisingly, this exercise suggests that the true effects are much larger than the results presented above because we cannot restrict our analysis to academic track students, instead estimating intent-to-treat effects. ${ }^{16}$ However, even these scaled-up estimates remain quantitatively rather small: For instance, the increase in the Stress Score of 0.064 units still amounts to less than $5 \%$ of a standard deviation. The second robustness check (column 3) presents the results for a placebo policy change that took place one year before the actual G8 reform. ${ }^{17}$ The effect of this placebo reform is small and statistically insignificant, suggesting that treatment and control group did not exhibit differential trends before the introduction of the G8 reform. This supports

\footnotetext{
${ }^{14}$ Results available upon request from the authors.

${ }^{15} \mathrm{We}$ also control for the main effect of the share of academic-track students.

${ }^{16}$ In these computations we basically assume a treatment effect of exactly zero for students in all other tracks. Aggregation is performed at the state level, which does not alter the point estimates, as we do not include any individual level information in the regressions and weight the state-level observations by the cell size (see Angrist and Pischke, 2008).

${ }^{17}$ Column 3 is based on equation (1) but additionally includes an indicator variable for the placebo policy reform that took place one year before. The displayed coefficient refers to the placebo reform indicator.
} 
the identification assumption of common trends.

The next set of robustness checks deals with alternative sample restrictions. First, we restrict the sample to only West German states, as in our observation period it is mainly West German states that switched from G9 to G8. Second, we extend the sample to include grades 5-12 (i.e., all the grades at academic track schools under the G8 regime). Third, we exclude the first G8 cohort in order to investigate whether the effects are mainly driven by transition effects. Fourth, while our health claims data of the German Social Health Insurance only include individuals with at least one doctor visit in a given year, we merge information on the size of the respective age group in a given county. We then extend our sample by the "missing observations" and assume that their value of the Stress Score is equal to $0 .{ }^{18}$ The results in columns (4) to (7) in Table 4 show that our findings are robust to these alternative sample restrictions. The last set of robustness checks address various estimation issues. As our main outcome variable, the Stress Score, is a count variable, we apply specific count data models: Poisson regression (column 8) and Negative Binomial regression (column 9). ${ }^{19}$ In column (10), we cluster the standard errors on the state-grade level. Again, the results are robust to these alternative specification.

\section{Conclusion}

This study contributes to our understanding of the interrelation between schooling and stress-related mental health problems among school children. More specifically, this study investigates the mental health consequences of a German schooling reform that substantially increased instruction time. Based on a difference-in-differences framework and stress-related outpatient diagnoses from the universe of health claims data of the German Social Health Insurance system, we find evidence that more instruction time slightly increases stress-related health problems of school children. The effects are robust to alternative model specifications.

This study contributes to the existing literature (i) by relying on a measure of stressrelated mental health problems that is reported by physicians and not by the affected individuals themselves; (ii) by focusing on the identification of causal effects; and (iii) by looking at a specific element of the schooling system. When interpreting the results

\footnotetext{
${ }^{18}$ Note that this is not our preferred specification. Our sample covers on average more than $85 \%$ of a county's population and the remaining $15 \%$ are not only individuals from the SHI system without doctor visit in a given year but also individuals with private health insurance who are not part of the SHI system (and who might have stress-related diagnoses as well). In our observation period, about 70 million individuals were insured in the German SHI system (German Federal Ministry of Health, 2018), meaning that across all age groups the SHI system covers about $87 \%$ of the population.

${ }^{19}$ The columns for the Poisson and Negative Binomial model display average marginal effects.
} 
of our study, several limitations have to be kept in mind. First, while an advantage of our outcome measure is that it is not reported by the affected individuals themselves, it might not be able to capture the full extent of additional stress induced by more instruction time, as some individuals might not visit a physician in case of stress. However, our outcome measure is clearly less extreme than (attempted) suicide, a measure used in previous research on schooling and health. Second, the data from the German Social Health Insurance system does not include information about the school track and the school grade, so that there is some measurement error in the assignment of the treatment indicator and, hence, our estimates can be seen as lower bounds.

Our results carry important insights both from public health and education perspectives. From a public health perspective, our results support the notion that school can cause stress in children. In general, we know very little whether and how schooling affects the mental health of children. More research is needed on which specific elements of the schooling system particularly affect children's mental health. Our findings do not mean that increasing weekly instruction time in school is a bad education policy. While previous research shows that more instruction time positively affects student performance (e.g. Marcotte, 2007; Sims, 2008; Herrmann and Rockoff, 2012; Carlsson et al., 2015), our results caution against pushing too hard to increase instruction time. The improved student performance must be weighed against the additional stress students experience. 


\section{References}

Ang, R. P. and Huan, V. S. (2006). Relationship between academic Stress and suicidal Ideation: Testing for Depression as a Mediator using multiple Regression. Child Psychiatry and Human Development, 37(2):133.

Angrist, J. D. and Pischke, J.-S. (2008). Mostly harmless econometrics: An empiricist's companion. Princeton university press.

Baltimore Center for Adolescent Health (2006). Confronting Teen Stress: Meeting the Challenge in Baltimore City. Technical report, Baltimore Center for Adolescent Health.

Banks, J. and Smyth, E. (2015). 'Your whole Life depends on it': Academic Stress and high-stakes Testing in Ireland. Journal of Youth Studies, 18(5):598-616.

Bokhari, F. and Schneider, H. (2011). School Accountability laws and the Consumption of Psychostimulants. Journal of Health Economics, 30(2):355-372.

Bor, W., Dean, A. J., Najman, J., and Hayatbakhsh, R. (2014). Are child and adolescent mental Health Problems increasing in the 21st Century? A systematic Review. Australian \& New Zealand Journal of Psychiatry, 48(7):606-616.

Büttner, B. and Thomsen, S. L. (2015). Are we spending too many Years in School? Causal Evidence of the Impact of shortening secondary School Duration. German Economic Review, 16(1):65-86.

Carlsson, M., Dahl, G. B., Öckert, B., and Rooth, D.-O. (2015). The Effect of Schooling on cognitive Skills. The Review of Economics and Statistics, 97(3):533-547.

Collishaw, S. (2015). Annual Research Review: Secular Trends in Child and adolescent mental Health. Journal of Child Psychology and Psychiatry, 56(3):370-393.

Collishaw, S., Maughan, B., Goodman, R., and Pickles, A. (2004). Time Trends in adolescent mental Health. Journal of Child Psychology and Psychiatry, 45(8):1350-1362.

Conner, J. O., Miles, S. B., and Pope, D. C. (2014). How many Teachers does it take to support a Student?: Examining the Relationship between Teacher Support and adverse Health Outcomes in high-performing, pressure-cooker High Schools. The High School fournal, 98(1):2242.

Dahmann, S. and Anger, S. (2014). The Impact of Education on Personality: Evidence from a German High School Reform. IZA Discussion Paper No. 8139.

Dahmann, S. C. (2017). How does Education improve cognitive Skills? Instructional Time versus Timing of Instruction. Labour Economics, 47:35-47. 
de Anda, D., Baroni, S., Boskin, L., Buchwald, L., Morgan, J., Ow, J., Gold, J. S., and Weiss, R. (2000). Stress, Stressors and Coping among High School Students. Children and Youth Services Review, 22(6):441-463.

Die Welt (2016). Kurze Schulzeit, mehr Stunden - der G8-Stress. http://www.welt.de/regionales/hamburg/article108288244/Kurze-Schulzeit-mehr-Stundender-G8-Stress.html, (accessed on September 17th, 2018).

Elias, M. J. (1989). Schools as a Source of Stress to Children: An Analysis of causal and ameliorative Influences. Journal of School Psychology, 27(4):393-407.

Eriksen, T. L. M., Nielsen, H. S., and Simonsen, M. (2014). Bullying in elementary school. fournal of Human Resources, 49(4):839-871.

F.A.Z. (2014). Warum ist G8 gescheitert? 23.02.2014, page 61.

Freeman, J. G., Samdal, O., Băban, A., and Bancila, D. (2012). The Relationship between School Perceptions and psychosomatic Complaints: Cross-country Differences across Canada, Norway, and Romania. School Mental Health, 4(2):95-104.

Galloway, M., Conner, J., and Pope, D. (2013). Nonacademic Effects of Homework in privileged, high-performing High Schools. The Journal of Experimental Education, 81(4):490-510.

German Federal Ministry of Health (2018). Gesetzliche Krankenversicherung - Kennzahlen und Faustformeln. Accessed: Januar 2018.

German Federal Statistical Office (2012). Allgemeinbildende Schulen: Fachserie 11, Reihe 1. https://Www.destatis.de/DE/Publikationen/Thematisch/ BildungForschungKultur/Schulen/BroschuereSchulenBlick.html.

Hansen, B. and Lang, M. (2011). Back to School Blues: Seasonality of Youth Suicide and the academic Calendar. Economics of Education Review, 30(5):850-861.

Heissel, J. A., Adam, E. K., Doleac, J. L., and Figlio, D. N. (2018). Testing, stress, and performance: How students respond physiologically to high-stakes testing. NBER Working Paper, 25305.

Herrmann, M. A. and Rockoff, J. E. (2012). Worker Absence and Productivity: Evidence from Teaching. Journal of Labor Economics, 30(4):749-782.

Hofmann, S. and Mühlenweg, A. (2018). Learning Intensity Effects in Students' mental and physical Health - Evidence from a large Scale natural Experiment in Germany. Economics of Education Review, 67:216-234.

Hübner, N., Wagner, W., Kramer, J., Nagengast, B., and Trautwein, U. (2017). Die G8-Reform in Baden-Württemberg: Kompetenzen, Wohlbefinden und Freizeitverhalten vor und nach der Reform. Zeitschrift für Erziehungswissenschaft, 20(4):748-771. 
Huebener, M., Kuger, S., and Marcus, J. (2017). Increased Instruction Hours and the widening Gap in Student Performance. Labour Economics, 47:15-34.

Huebener, M. and Marcus, J. (2015). Empirische Befunde zu Auswirkungen der G8Schulzeitverkürzung. DIW Roundup, 57.

Huebener, M. and Marcus, J. (2017). Compressing Instruction Time into fewer Years of Schooling and the Impact on Student Performance. Economics of Education Review, 58:1-18.

Jewett, R., Sabiston, C. M., Brunet, J., O'Loughlin, E. K., Scarapicchia, T., and O'Loughlin, J. (2014). School Sport Participation during Adolescence and mental Health in early Adulthood. fournal of Adolescent Health, 55(5):640-644.

King, M. D., Jennings, J., and Fletcher, J. M. (2014). Medical Adaptation to academic Pressure: Schooling, Stimulant use, and socioeconomic Status. American Sociological Review, 79(6):1039-1066.

Lahti, A., Räsänen, P., Karvonen, K., Särkioja, T., Meyer-Rochowm, V. B., and Hakko, H. (2005). Autumn peak in Shooting Suicides of Children and Adolescents from Northern Finland. Neuropsychobiology, 54(2):140-146.

Leung, G. S., Yeung, K. C., and Wong, D. F. (2010). Academic Stressors and Anxiety in Children: The Role of paternal Support. Journal of Child and Family studies, 19(1):90-100.

Löfstedt, P. (2017). Why are psychosomatic Symptoms in young People increasing in Sweden? European fournal of Public Health, 27(Supplement 3):388.

Marcotte, D. E. (2007). Schooling and Test Scores: A mother-natural Experiment. Economics of Education Review, 26(5):629-640.

Marcus, J. and Zambre, V. (2018). The Effect of Increasing Education Efficiency on University Enrollment: Evidence from administrative Data and an unusual Schooling Reform in Germany. fournal of Human Resources.

Matsubayashi, T., Ueda, M., and Yoshikawa, K. (2016). School and Seasonality in Youth Suicide: Evidence from Japan. Journal of Epidemiology and Community Health, 70(11):1122-1127.

Meyer, T. and Thomsen, S. L. (2015). Schneller fertig, aber weniger Freizeit? - Eine Evaluation der Wirkungen der verkürzten Gymnasialschulzeit auf die außerschulischen Aktivitäten der Schülerinnen und Schüler. Schmollers Fahrbuch, 135(3):249-277.

Meyer, T. and Thomsen, S. L. (2016). How important is Secondary School Duration for postschool Education Decisions? Evidence from a natural Experiment. Fournal of Human Capital, 10(1):249-278. 
Milde-Busch, A., Blaschek, A., Borggräfe, I., Von Kries, R., Straube, A., and Heinen, F. (2010). Besteht ein Zusammenhang zwischen der verkürzten Gymnasialzeit und Kopfschmerzen und gesundheitlichen Belastungen bei Schülern im Jugendalter? Klinische Pädiatrie, 222(04):255260.

Quis, J. S. (2018). Does compressing High School Duration affect Students' Stress and mental Health? Evidence from the National Educational Panel Study. Fournal of Economics and Statistics, 235(5).

Quis, J. S. and Reif, S. (2017). Health Effects of Instruction Intensity - Evidence from a natural Experiment in German High-Schools. FAU Discussion Papers in Economics, 12-2017.

Ravens-Sieberer, U., Ellert, U., and Erhart, M. (2007). Gesundheitsbezogene Lebensqualität von Kindern und Jugendlichen in Deutschland. Bundesgesundheitsblatt-GesundheitsforschungGesundheitsschutz, 50(5-6):810-818.

Ravens-Sieberer, U., Freeman, J., Kokonyei, G., Thomas, C. A., and Erhart, M. (2009). School as a Determinant for Health Outcomes - A structural Equation Model Analysis. Health Education, 109(4):342-356.

RKI (2015). The german health survey for children and adolescents (kiggs wave 1). public use file. Robert Koch Institute, Department of Epidemiology and Health Monitoring.

Rouche, A., Erhart, M., and von Stillfried, D. (2017). A Stress Index based on ambulatory Claims Data for the Detection of mental Causes of Health Complaints. In WPA XVII World Congress of Psychiatry (2017 Oct 8-12; Berlin, Germany.).

Schwandt, H. and Wuppermann, A. (2016). The Youngest get the Pill: ADHD Misdiagnosis in Germany, its regional Correlates and international Comparison. Labour Economics, 43:72-86.

Sims, D. P. (2008). Strategic Responses to School Accountability Measures: It's all in the Timing. Economics of Education Review, 27(1):58-68.

Song, H. (2017). The Cost of attending an Elite College. Economics Letters, 159:173-176.

Spiegel Online (2016). Streit über G8: Bayerns Schulminister erklärt Turbo-Abitur für „überholt“. http://www.spiegel.de/schulspiegel/wissen/abitur-g8-spaenle-nennt-turbo-gymnasiumueberholt-a-959660.html, (accessed on September 17th, 2018).

Thiel, H., Thomsen, S. L., and Büttner, B. (2014). Variation of learning Intensity in late Adolescence and the Effect on Personality Traits. Journal of the Royal Statistical Society: Series A (Statistics in Society), 177(4):861-892.

Thomsen, S. L. and Anger, S. (2018). Die Notwendigkeit ökonomischer Politikberatung für eine evidenzbasierte Bildungspolitik: Verkürzung und Verlängerung der Schulzeit am Gymnasium. Perspektiven der Wirtschaftspolitik, 19(3):167-184. 
Torsheim, T. and Wold, B. (2001). School-related Stress, School Support, and somatic Complaints: A general Population Study. Fournal of Adolescent Research, 16(3):292-303.

Vossenkuhl, A. (2010). (Berufs-)Schulpflicht in Deutschland. Berufsbildung in Wissenschaft und Praxis, 39(6):53-54.

WHO (2016). Growing up unequal: gender and socioeconomic differences in young people's health and well-being. Health behaviour in school-aged children (HBSC) study: itternational report from the 2013/2014 survey. World Health Organization, Copenhagen. 


\section{Figures and Tables}

Figure 1: Increase in instruction hours due to reform

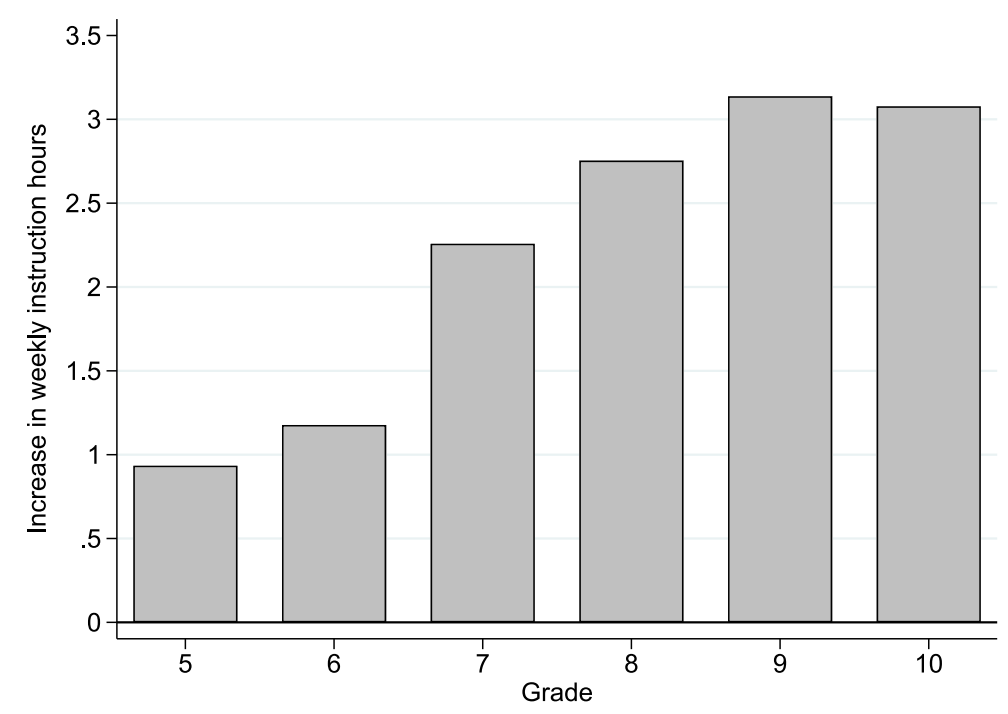

Notes: Grade specific changes in weekly instruction hours due to the G8 reform. Adapted from Huebener et al. (2017). The average increases are estimated from official timetable regulations for our estimation sample. 
Table 1: Overview over the implementation of the G8 reform across German states

\begin{tabular}{lccc}
\hline & $\begin{array}{c}\text { First affected } \\
\text { cohort in grade } 7\end{array}$ & $\begin{array}{c}\text { First affected } \\
\text { birth cohort }\end{array}$ & $\begin{array}{c}\text { First G8 } \\
\text { graduates }\end{array}$ \\
\hline Change from G9 to G8 & & & \\
Saxony-Anhalt (ST) & 2001 & $06 / 1988$ & 2007 \\
Mecklenburg-Vorpommern (MV) & 2002 & $06 / 1989$ & 2008 \\
Saarland (SL) & 2003 & $07 / 1990$ & 2009 \\
Hamburg (HH) & 2004 & $07 / 1991$ & 2010 \\
Bavaria (BY) & 2005 & $07 / 1992$ & 2011 \\
Lower-Saxony (NI) & 2005 & $07 / 1992$ & 2011 \\
Baden-Württemberg (BW) & 2006 & $07 / 1993$ & 2012 \\
Bremen (HB) & 2006 & $07 / 1993$ & 2012 \\
Berlin (BE) & 2006 & $07 / 1993$ & 2012 \\
Brandenburg (BB) & 2006 & $06 / 1993$ & 2012 \\
Hesse (HE) & 2006 & $07 / 1993$ & 2012 \\
North Rhine-Westphalia (NW) & 2007 & $07 / 1994$ & 2013 \\
Schleswig-Holstein (SH) & 2010 & $07 / 1997$ & 2016 \\
Always G8 & & & \\
Saxony (SN) & all & all & all \\
Thuringia (TH) & all & all & all \\
Always G9 & & & none \\
Rhineland-Palatinate (RP) & none & none &
\end{tabular}

Notes: Overview over the introduction of the G8 reform across German states. Several states have announced that they will abolish the G8 reform and switch back to the old system with 13 years of schooling, including Lower Saxony (last G8 graduates in 2019), Bavaria (last G8 graduates in 2024), North Rhine-Westphalia (last G8 graduates in 2024), and Schleswig-Holstein (last G8 graduates in 2025). In Hesse, the majority of academic track schools abolished the G8 reform at different points in time. All switch-backs take place after our observation period. 
Figure 2: Distribution of the Disease based Stress Score (DbSS)

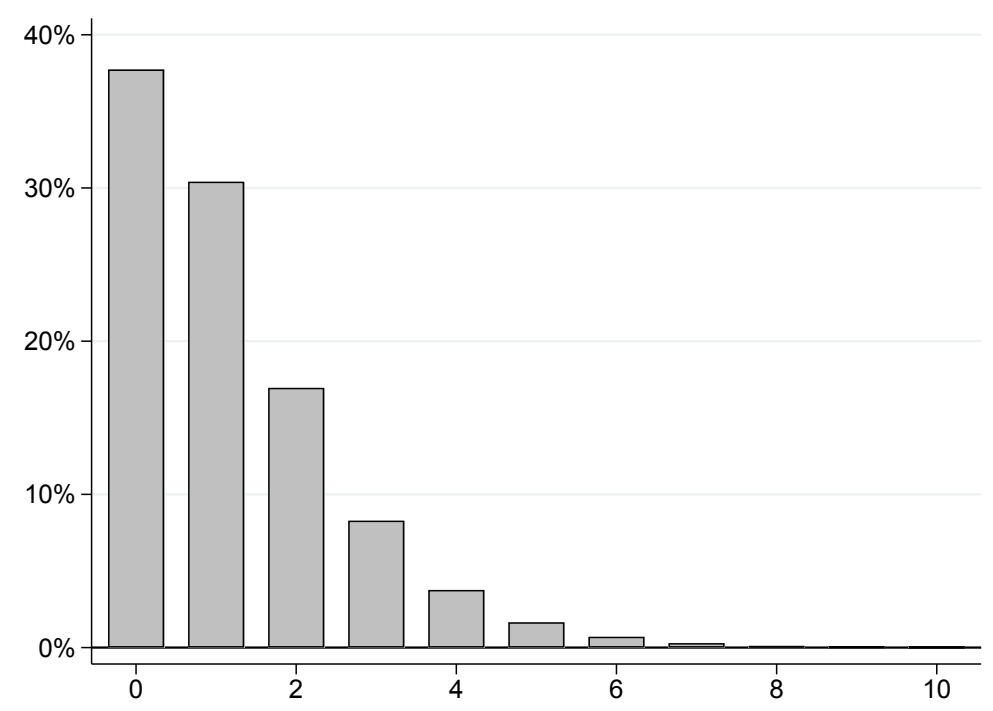

Notes: The distribution of the Stress Score in our sample. Source: Own calculation based on German health insurance claims data. 
Table 2: Effect of the G8 reform on the Stress Score

\begin{tabular}{|c|c|c|c|c|}
\hline & Mean & (1) & (2) & (3) \\
\hline \multicolumn{5}{|c|}{ Panel A: Stress Scale } \\
\hline G8 reform & 1.208 & $\begin{array}{l}0.022^{* *} \\
(0.009)\end{array}$ & $\begin{array}{l}0.022^{* *} \\
(0.009)\end{array}$ & $\begin{array}{l}0.018^{* *} \\
(0.008)\end{array}$ \\
\hline \multicolumn{5}{|c|}{ Panel B: Pr(Stress Scale > 0) } \\
\hline G8 reform & .623 & $\begin{array}{l}0.006^{* *} \\
(0.003)\end{array}$ & $\begin{array}{l}0.006^{* *} \\
(0.003)\end{array}$ & $\begin{array}{c}0.006^{* * *} \\
(0.002)\end{array}$ \\
\hline \multicolumn{5}{|c|}{ Panel C: Pr(Stress Scale > 1) } \\
\hline G8 reform & .319 & $\begin{array}{l}0.006^{* *} \\
(0.003)\end{array}$ & $\begin{array}{l}0.006^{* *} \\
(0.003)\end{array}$ & $\begin{array}{l}0.005^{* *} \\
(0.002)\end{array}$ \\
\hline \multicolumn{5}{|c|}{ Panel D: Pr(Stress Scale > 2) } \\
\hline G8 reform & .15 & $\begin{array}{l}0.005^{* *} \\
(0.002)\end{array}$ & $\begin{array}{l}0.005^{* *} \\
(0.002)\end{array}$ & $\begin{array}{l}0.003^{*} \\
(0.002)\end{array}$ \\
\hline \multicolumn{5}{|c|}{ Panel E: Pr(Stress Scale $>3)$} \\
\hline G8 reform & .067 & $\begin{array}{l}0.003^{* *} \\
(0.001)\end{array}$ & $\begin{array}{l}0.003^{* *} \\
(0.001)\end{array}$ & $\begin{array}{l}0.002^{*} \\
(0.001)\end{array}$ \\
\hline $\mathrm{N}$ & & $10,056,859$ & $10,056,859$ & $10,056,859$ \\
\hline Cohort FE: & & yes & yes & yes \\
\hline County FE: & & yes & yes & yes \\
\hline Grade FE: & & yes & yes & yes \\
\hline CohortXGrade FE: & & - & yes & yes \\
\hline CountyXGrade FE: & & - & - & yes \\
\hline
\end{tabular}

Notes: The tables displays the effect of the G8 reform on stress-related outpatient diagnoses. Standard errors are clustered at the cohort-state level. ${ }^{*} p<0.1$, ${ }^{*}$ $p<0.05,{ }^{* * *} p<0.01$. 
Table 3: Effect in different grades

\begin{tabular}{lccccc}
\hline & Stress & \multicolumn{4}{c}{ Stress Score larger than } \\
\cline { 3 - 6 } & Score & 0 & 1 & 2 & 3 \\
\hline Grade 7 & 0.021 & 0.006 & 0.006 & $0.005^{* *}$ & $0.003^{*}$ \\
& $(0.013)$ & $(0.004)$ & $(0.004)$ & $(0.003)$ & $(0.002)$ \\
Grade 8 & 0.011 & 0.002 & 0.004 & 0.003 & 0.002 \\
& $(0.014)$ & $(0.005)$ & $(0.004)$ & $(0.003)$ & $(0.002)$ \\
Grade 9 & $0.032^{* * *}$ & $0.009^{* * *}$ & $0.009^{* * *}$ & $0.007^{* * *}$ & $0.004^{* * *}$ \\
& $(0.009)$ & $(0.003)$ & $(0.003)$ & $(0.002)$ & $(0.001)$ \\
Grade 10 & $0.018^{*}$ & 0.005 & $0.005^{*}$ & 0.004 & 0.002 \\
& $(0.011)$ & $(0.003)$ & $(0.003)$ & $(0.002)$ & $(0.001)$ \\
N & $10,056,859$ & $10,056,859$ & $10,056,859$ & $10,056,859$ & $10,056,859$ \\
\hline
\end{tabular}

Notes: ${ }^{*} p<0.1,{ }^{* *} p<0.05,{ }^{* * *} p<0.01$.

Table 4: Robustness tests

\begin{tabular}{|c|c|c|c|c|c|c|c|c|c|c|}
\hline & \multirow[b]{2}{*}{$\begin{array}{l}\text { Main } \\
(1)\end{array}$} & \multirow[b]{2}{*}{$\begin{array}{l}\text { Scale-up } \\
\quad(2)\end{array}$} & \multirow[b]{2}{*}{$\begin{array}{l}\text { Placebo } \\
\text { reform } \\
\text { (3) }\end{array}$} & \multicolumn{4}{|c|}{ Alternative samples } & \multicolumn{3}{|c|}{ Estimation issues } \\
\hline & & & & $\begin{array}{l}\text { Only } \\
\text { West } \\
(4)\end{array}$ & $\begin{array}{c}\text { Grades } \\
5-12 \\
(5)\end{array}$ & $\begin{array}{l}\text { Excluding } \\
\text { first G8 } \\
\text { (6) }\end{array}$ & $\begin{array}{l}\text { Full } \\
\text { popul. } \\
\text { (7) }\end{array}$ & $\begin{array}{l}\text { Poisson } \\
\quad(8)\end{array}$ & $\begin{array}{l}\text { Negative } \\
\text { binomial } \\
(9)\end{array}$ & $\begin{array}{l}\text { State-grade } \\
\text { cluster } \\
(10)\end{array}$ \\
\hline \multicolumn{11}{|c|}{ Panel A: Stress Scale } \\
\hline G8 reform & $\begin{array}{l}0.022^{* \star} \\
(0.009)\end{array}$ & $\begin{array}{l}0.064^{* * *} \\
(0.027)\end{array}$ & $\begin{array}{c}0.008 \\
(0.015)\end{array}$ & $\begin{array}{l}0.019^{\star *} \\
(0.009)\end{array}$ & $\begin{array}{l}0.019^{* *} \\
(0.008)\end{array}$ & 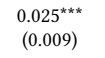 & $\begin{array}{l}0.021^{* *} \\
(0.009)\end{array}$ & $\begin{array}{l}0.022^{* *} \\
(0.009)\end{array}$ & $\begin{array}{l}0.022^{\text {** }} \\
(0.009)\end{array}$ & $\begin{array}{l}0.022^{* *} \\
(0.009)\end{array}$ \\
\hline \multicolumn{11}{|c|}{ Panel B: $\operatorname{Pr}($ Stress Scale $>0)$} \\
\hline G8 reform & $\begin{array}{l}0.006^{* *} \\
(0.003)\end{array}$ & $\begin{array}{l}0.017^{\star *} \\
(0.008)\end{array}$ & $\begin{array}{c}0.001 \\
(0.004)\end{array}$ & $\begin{array}{l}0.006^{* *} \\
(0.003)\end{array}$ & $\begin{array}{c}0.003 \\
(0.002)\end{array}$ & $\begin{array}{l}0.006^{* *} \\
(0.003)\end{array}$ & $\begin{array}{l}0.006^{*} \\
(0.003)\end{array}$ & & & $\begin{array}{l}0.006^{* *} \\
(0.003)\end{array}$ \\
\hline \multicolumn{11}{|c|}{ Panel C: $\operatorname{Pr}($ Stress Scale > 1) } \\
\hline G8 reform & $\begin{array}{l}0.006^{* *} \\
(0.003)\end{array}$ & $\begin{array}{l}0.018^{\text {** }} \\
(0.008)\end{array}$ & $\begin{array}{c}0.003 \\
(0.004)\end{array}$ & $\begin{array}{l}0.006^{* *} \\
(0.003)\end{array}$ & $\begin{array}{l}0.005^{\star *} \\
(0.002)\end{array}$ & $\begin{array}{l}0.007^{* *} \\
(0.003)\end{array}$ & $\begin{array}{l}0.006^{\star *} \\
(0.003)\end{array}$ & & & $\begin{array}{l}0.006^{* *} \\
(0.003)\end{array}$ \\
\hline \multicolumn{11}{|c|}{ Panel D: $\operatorname{Pr}($ Stress Scale > 2) } \\
\hline G8 reform & $\begin{array}{l}0.005^{* *} \\
(0.002)\end{array}$ & $\begin{array}{l}0.014^{* *} \\
(0.006)\end{array}$ & $\begin{array}{c}0.002 \\
(0.003)\end{array}$ & $\begin{array}{l}0.004^{*} \\
(0.002)\end{array}$ & $\begin{array}{c}0.005^{\star * *} \\
(0.002)\end{array}$ & $\begin{array}{c}0.006^{* * *} \\
(0.002)\end{array}$ & $\begin{array}{l}0.004^{\star *} \\
(0.002)\end{array}$ & & & $\begin{array}{l}0.005^{\star *} \\
(0.002)\end{array}$ \\
\hline \multicolumn{11}{|c|}{ Panel E: $\operatorname{Pr}($ Stress Scale $>3)$} \\
\hline G8 reform & $\begin{array}{l}0.003^{* *} \\
(0.001)\end{array}$ & $\begin{array}{l}0.008^{\star *} \\
(0.003)\end{array}$ & $\begin{array}{c}0.001 \\
(0.002)\end{array}$ & $\begin{array}{l}0.002^{*} \\
(0.001)\end{array}$ & $\begin{array}{c}0.003^{* * *} \\
(0.001)\end{array}$ & $\begin{array}{c}0.003^{* * *} \\
(0.001)\end{array}$ & $\begin{array}{l}0.002^{\star *} \\
(0.001)\end{array}$ & & & $\begin{array}{l}0.003^{* *} \\
(0.001)\end{array}$ \\
\hline $\mathrm{N}$ & $10,056,859$ & 240 & $10,056,859$ & $8,526,879$ & $20,740,983$ & $9,046,365$ & $11,716,151$ & $10,056,859$ & $10,056,859$ & $10,056,859$ \\
\hline
\end{tabular}

Notes: All regressions control for cohort, county and grade fixed effects. Standard errors are clustered at the cohort-state level. ${ }^{*} p<0.1,{ }^{* *} p<0.05,{ }^{* * *} p<0.01$. 


\section{Appendix}

Table A.1: Population share in SHI

\begin{tabular}{llll}
\hline & Share SHI & Share High School & $\mathrm{N}$ \\
\hline All aged 10-17 & $88.99 \%$ & $35.80 \%$ & 6,375 \\
All aged 12-15 & $88.65 \%$ & $34.02 \%$ & 3,796 \\
High School students aged 12-15 & $79.91 \%$ & $100 \%$ & 1,310 \\
\hline
\end{tabular}

Notes: Based on the KiGGS survey (RKI, 2015). Shares of individuals in the social health insurance (SHI) or academic track schools (High School). Shares obtained using cross sectional weights.

Figure A.1: Health and Satisfaction with School

Headache

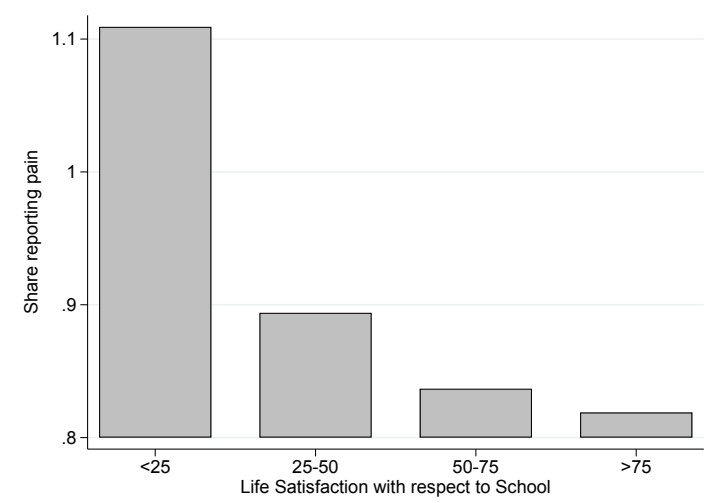

Backpain

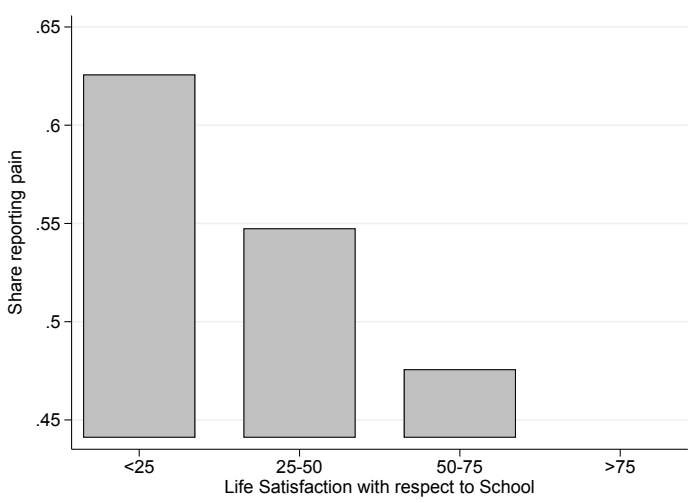

Abdominal Pain

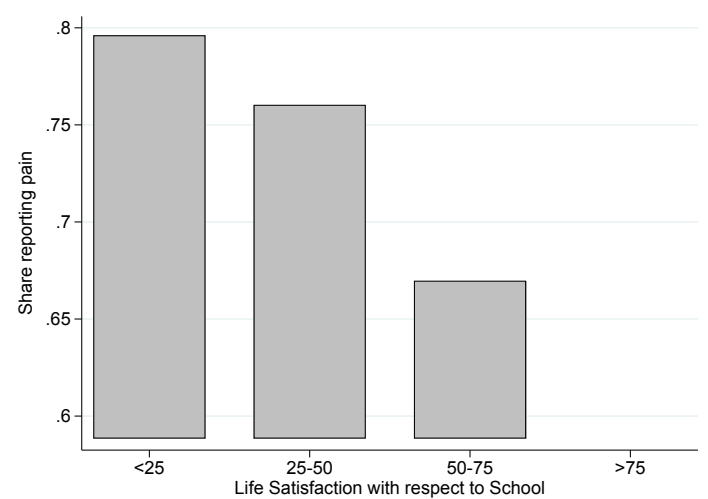

Low Self Assessed Health

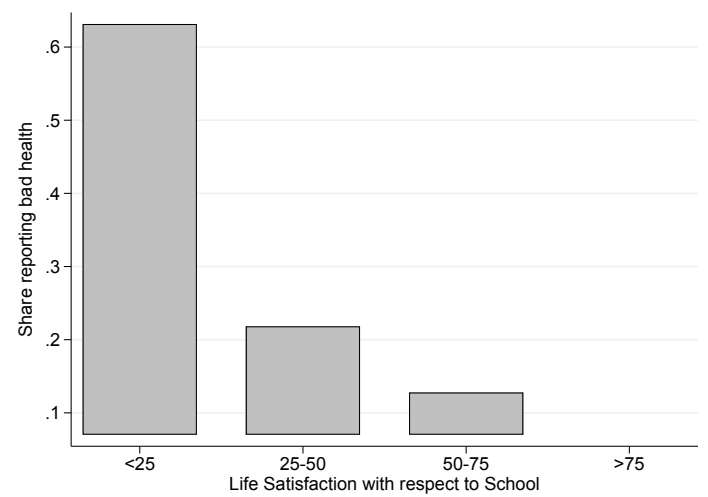

Notes: Based on the KiGGS survey (RKI, 2015). Health problems related to stress and standardized life satisfaction with respect to school. The satisfaction scale ranges from 0 (lowest satisfaction) to 100 (highest satisfaction); for details, see Ravens-Sieberer et al. (2007). Health indicators are whether there was any headache, abdominal pain, or back pain in the last three months as well as self-assessed health on a scale from $1=$ very good to $5=$ very bad, worse or equal to 3 . 